Article

\title{
Free-Radical-Mediated Formation of Trans-Cardiolipin Isomers, Analytical Approaches for Lipidomics and Consequences of the Structural Organization of Membranes ${ }^{\dagger}$
}

\author{
Fabrizio Vetica ${ }^{1}{ }^{\oplus}$, Anna Sansone ${ }^{1}\left(\mathbb{D}\right.$, Cesare Meliota ${ }^{1}$, Gessica Batani ${ }^{1}$, Marinella Roberti ${ }^{2}$, \\ Chryssostomos Chatgilialoglu $1,3, *(\mathbb{D})$ and Carla Ferreri ${ }^{1, *(\mathbb{D})}$ \\ 1 Istituto per la Sintesi Organica e la Fotoreattività, Consiglio Nazionale delle Ricerche, Via Piero Gobetti 101, \\ 40129 Bologna, Italy; fabrizio.vetica@isof.cnr.it (F.V.); anna.sansone@isof.cnr.it (A.S.); \\ cesare.meliota@studio.unibo.it (C.M.); gessica.batani@studio.unibo.it (G.B.) \\ 2 Department of Pharmacy and Biotechnology, University of Bologna, Via Belmeloro 6, 40126 Bologna, Italy; \\ marinella.roberti@unibo.it \\ 3 Center for Advanced Technologies, Adam Mickiewicz University, 61-614 Poznań, Poland \\ * Correspondence: chrys@isof.cnr.it (C.C.); carla.ferreri@isof.cnr.it (C.F.) \\ + This article is dedicated to Prof. Bronisław Marciniak, an example of unswerving motivation toward \\ progress, in the occasion of his 70th birthday.
}

Received: 20 July 2020; Accepted: 12 August 2020; Published: 15 August 2020

check for updates

\begin{abstract}
Free-radical-mediated processes, such as peroxidation, isomerization and hydrogenation affecting fatty acid integrity and biological functions, have a trans-disciplinary relevance. Cardiolipins (CL, (1,3-diphosphatidyl-sn-glycerol)) and tetra-linoleoyl-CL are complex phospholipids, exclusively present in the Inner Mitochondrial Membrane (IMM) lipids, where they maintain membrane integrity and regulate enzyme functionalities. Peroxidation pathways and fatty acid remodeling are known causes of mitochondrial disfunctions and pathologies, including cancer. Free-radical-mediated isomerization with the change of the cis CL into geometrical trans isomers is an unknown process with possible consequences on the supramolecular membrane lipid organization. Here, the formation of mono-trans CL (MT-CL) and other trans CL isomers (T-CL) is reported using CL from bovine heart mitochondria and thiyl radicals generated by UV-photolysis from 2-mercaptoethanol. Analytical approaches for $\mathrm{CL}$ isomer separation and identification via ${ }^{1} \mathrm{H} /{ }^{13} \mathrm{C}$ NMR are provided, together with the chemical study of CL derivatization to fatty acid methyl esters (FAME), useful for lipidomics and metabolomics research. Kinetics information of the radical chain isomerization process was obtained using $\gamma$-irradiation conditions. The CL isomerization affected the structural organization of membranes, as tested by the reduction in unilamellar liposome diameter, and accompanied the well-known process of oxidative consumption induced by Fenton reagents. These results highlight a potential new molecular modification pathway of mitochondrial lipids with wide applications to membrane functions and biological consequences.
\end{abstract}

Keywords: cardiolipin; linoleic acid; free radicals; cis-trans isomerization; $\gamma$-irradiation; Fenton reaction; liposome dimension

\section{Introduction}

In lipid chemistry, the free-radical-mediated cis-trans isomerization process contributes, together with hydrogenation and lipid peroxidation processes, to cause alteration of the naturally occurring unsaturated fatty-acid-containing lipids [1-3]. These processes have a trans-disciplinary relevance, 
being identified in biological pathways of radical stress as well as in industrial food and nutraceutical production [3-6]. Analytical protocols have been established to determine trans lipid presence in living organisms as well as in nutraceutical formulations, which can affect health [4-6].

Cardiolipin (CL) is a unique phospholipid, which is localized and synthesized in the inner mitochondrial membrane (IMM), where it represents a fairly high percentage of the total lipids (about $25 \%$ of the total lipid composition of bovine heart mitochondria) [7-9]. It is characterized by a bi-phospholipid structure, bridged by an additional glycerol moiety, and four fatty acid residues (Figure 1). This distinctive dimeric structure has a conical shape, therefore imparting a peculiar contribution in the formation of lipid bilayers, causing the extensive folding of the IMM cristae [10]. The type of the CL fatty acid residues is intriguing from the chemical biology point of view. The immature CL, containing mainly palmitic (16:0) and oleic (9cis-18:1) acids, is remodeled by de-acylation and trans-acylation reactions affording the final composition of mature CL, containing predominantly polyunsaturated fatty acids (PUFAs) with linoleic acid (9cis,12cis-18:2) as the most abundant residue [11, 12]. For instance, bovine heart cardiolipin contains $95 \%$ of linoleic acid, while the remaining $5 \%$ is constituted by vaccenic acid (11cis-18:1) and a few other saturated and unsaturated FAs [13]. The enrichment of PUFAs such as linoleic acid is well known to be crucial for the lipid organization of the IMM and binding with the complexes I, III, IV, V, of the respiratory chain, also stabilizing the super complexes [14].

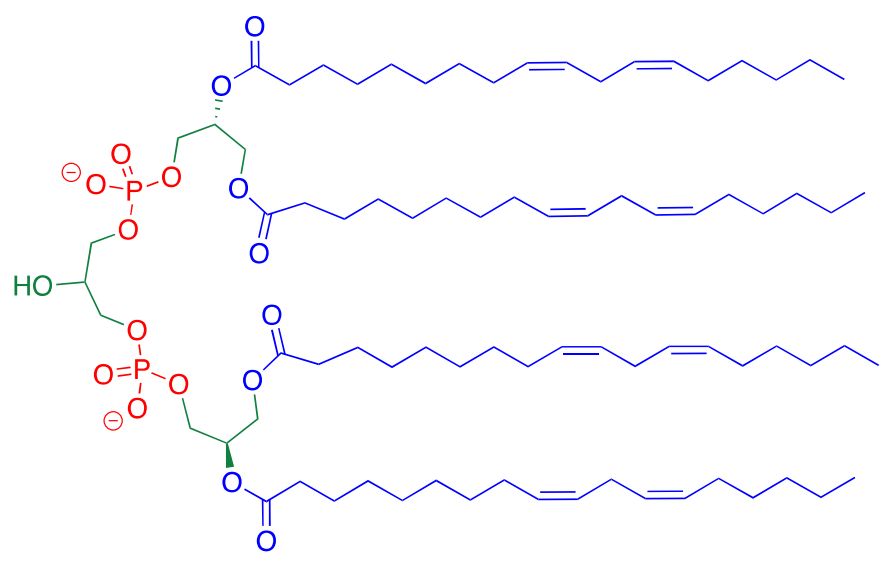

Figure 1. Structure of tetra-linoleoyl cardiolipin.

The structural contribution of $\mathrm{CL}$ is paralleled by a very important chemical contribution in the frame of the mitochondrial free radical reactivity, particularly focusing on the reactivity of tetra-linoleoyl-CL (Figure 1). The bisallylic H-atoms of the linoleoyl residues can be abstracted by an oxygen-centered radical (for example, a peroxyl radical generated under the conditions of mitochondrial stress). Subsequent reaction with molecular oxygen and the generation of a lipid peroxyl radical activate the chain process, which is responsible for the intrinsic apoptotic pathway with release of cytochrome c [15].

We were interested by the fact that double bond isomerization was never reported for $\mathrm{CL}$, although such a process cannot be ruled out if one considers the mechanism of thiyl radical-catalyzed reversible addition to lipids (L); it occurs with the radical mechanism shown in Figure 2a, consisting of a reversible addition of thiyl radical (RS ${ }^{\bullet}$ ) to the double bond forming the trans geometry as the most thermodynamically favorable structure. It is worth noting that (i) the radical RS ${ }^{\bullet}$ acts as a catalyst for cis-trans isomerization, and (ii) positional isomers cannot be reaction products because the mechanism does not allow a double bond shift $[2,16,17]$. Considering polyunsaturated substrates, the isomerization mechanism occurs as a step-by-step process, i.e., each isolated double bond behaves independently (Figure 2b) [18,19]. With linoleic-acid-containing liposomes and micelles, we demonstrated that the mono-trans isomers $\left(\mathbf{L}_{\mathrm{EZ}}, \mathbf{L}_{\mathrm{ZE}}\right)$ are the first formed products and the competition with peroxidation occurs under oxygen conditions [20]. Moreover, we examined kinetics and products of the thiyl radical 
reaction with methyl linoleate, thus completing the picture of PUFA reactivity [19]. This knowledge supports the feasibility of cis-trans CL isomerization by free radical stress that could occur in the specific mitochondrial environment. So far, this transformation is unknown.

(a)

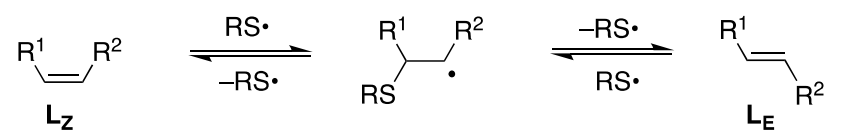

(b)

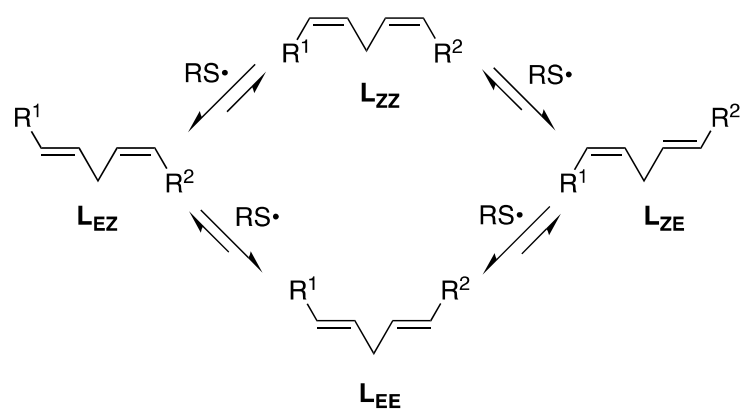

Figure 2. (a) Thiyl radical-catalyzed isomerization of monounsaturated fatty acid moiety $\mathbf{L}_{\mathbf{Z}}$ to $\mathbf{L}_{\mathbf{E}}$;

(b) Cis-trans isomerization of linoleic moiety $\left(\mathbf{L}_{\mathbf{Z Z}}\right)$ catalyzed by thiyl radicals.

The analytical aspect concerning the identification of trans CL isomers is a crucial issue to address, with the specific goal to have protocols that can examine biological specimens. At present, CL analysis includes: (i) the isolation of CL via preparative thin layer chromatography (TLC) and transesterification to obtain the corresponding fatty acid methyl esters (FAME) under acidic conditions ( $\mathrm{HCl}, \mathrm{H}_{2} \mathrm{SO}_{4}$ or $\mathrm{BF}_{3}$ in methanol) to proceed with the gas chromatographic (GC) identification of the fatty acid residues [21-24]; (ii) HPLC with tandem MS/MS analysis to identify cardiolipins among other lipid classes [25-29]. Based on our experience in fatty acid-based lipidomics [2,19], the transesterification conditions must ensure a quantitative performance and the analytical conditions need to separate and identify cis and trans isomers. From the biological point of view, it is worth underlining that fatty acid double bonds are generated stereo- and regio-specifically by desaturase enzymes [30], and only the cis geometry provides the known membrane asset and signaling properties $[31,32]$. The permeability and fluidity of the membranes are profoundly affected by the cis-trans isomerization of unsaturated fatty acids, as demonstrated for membrane biophysical and dimensional properties using cis and trans monounsaturated fatty acid (MUFA) residues [33-35]. We also showed that conditions of cellular stress cause the degradation of sulfur-containing proteins and the formation of diffusible thiyl radicals able to induce cis-trans isomerization in unsaturated lipid vesicles [2,36].

In the frame of our research on mono-trans PUFA isomers as biomarkers to be used to detect isomerization in cells [37,38], animals [39,40] and humans [41-43], we wish to present our results on the identification and characterization of trans CL isomers by thiyl radical-catalyzed cis-trans isomerization of bovine hearth CL employing photolysis and $\gamma$-radiolysis techniques. Furthermore, we developed the analytical protocol for the recognition of trans $\mathrm{CL}$ via ${ }^{1} \mathrm{H}$ and ${ }^{13} \mathrm{C}$ NMR and gave a fully calibrated procedure for CL transesterification into their corresponding FAME for GC analysis. We also performed liposome experiments to mimic trans CL formation in membranes addressing the influence of geometrical isomerism on the compartment formation process and the relationship with oxidative processes. 


\section{Materials and Methods}

Unless otherwise noted, all commercially available compounds were used without further purification. Water was purified with a Millipore system. Bovine hearth cardiolipin and 2-oleoyl-1-palmitoyl-sn-glycero-3-phosphocholine (POPC) were purchased from Larodan Inc (Solna, Sweden); Ferrous ammonium sulfate $\mathrm{Fe}\left(\mathrm{NH}_{4}\right)_{2}\left(\mathrm{SO}_{4}\right)_{2} \times 6 \mathrm{H}_{2} \mathrm{O}$ (Fe II AS, Carlo Erba, Milan, Italy) $\left(\mathrm{Na}_{2} \mathrm{~S} \times 9 \mathrm{H}_{2} \mathrm{O}\right.$ Merck, Milan, Italy), $\mathrm{H}_{2} \mathrm{O}_{2} 30 \%$ and 2-mercaptoethanol (Merck, Milan, Italy); chloroform, methanol, diethyl ether and $n$-hexane (HPLC grade) were used as received from J. T. Baker, Phillipsburg, $\mathrm{NJ}$, USA. MeOH- $\mathrm{d}_{4}$ and DMSO- $\mathrm{d}_{6}$ were purchased from Merck (Milan, Italy). NMR spectra were recorded at ambient temperature on a Varian $500 \mathrm{MHz}$ spectrometer (Agilent, Cernusco sul Naviglio, Milan, Italy). Solvents are detailed for each spectrum. UV spectra were recorded at room temperature with a Cary300Bio spectrophotometer (Agilent, Cernusco sul Naviglio, Milan, Italy). Hydrodynamic diameters of the obtained liposomes were measured using the dynamic light scattering (DLS) technique (Malvern Instruments Series NanoZS with a detection angle of $173^{\circ}$, Malvern Instruments, Malvern, UK). All measurements were recorded at $25^{\circ} \mathrm{C}$.

\subsection{Transesterification Procedure and Gas Chromatography (GC) Analysis}

The transesterification protocol optimized for bovine hearth cardiolipin and applied to the phospholipids extracted from liposome suspensions was performed taking care of dry conditions, as follows: $0.5 \mathrm{mg}$ of $\mathrm{CL}$ were dissolved in $0.5 \mathrm{~mL}$ of a $22 \mathrm{mM} \mathrm{NaOMe}$ solution in $\mathrm{MeOH}$ corresponding to 32 equiv. in respect of CL, i.e., 8 equiv. in respect of each FA chain (see in Supporting Materials the details of this preparation) and the resulting mixture was stirred for $2 \mathrm{~h}$ at room temperature in a close vessel, under nitrogen atmosphere. Thin-layer chromatography was used to monitor the progress of CL transformation. Eluent: $\mathrm{CHCl}_{3} / \mathrm{MeOH} / \mathrm{H}_{2} \mathrm{O}$ 5:2:0.2, and $\mathrm{R}_{\mathrm{f}}\left(\right.$ lyso-CL) $=0.32, \mathrm{R}_{\mathrm{f}}(\mathrm{CL})=0.65$, $\mathrm{R}_{\mathrm{f}}(18: 2$ acid $)=0.88, \mathrm{R}_{\mathrm{f}}(18: 2$ methyl ester $)=1$, to also evidence the hydrolysis of the starting material. After the elapsed time, the reaction mixture was extracted with $n$-hexane $(3 \times 2 \mathrm{~mL})$ containing $0.1 \mathrm{~mL}$ of a standard solution of 17:0 methyl ester; $n$-hexane was then evaporated, the residue dissolved in again in $1 \mathrm{~mL}$ of $n$-hexane and $1 \mu \mathrm{L}$ was injected in GC.

Fatty acid methyl esters (FAME) were analyzed by GC (Agilent 6850, Agilent, Cernusco sul Naviglio, Milan, Italy), using the split mode (50: 1), equipped with a $60 \mathrm{~m} \times 0.25 \mathrm{~mm} \times 0.25 \mu \mathrm{m}$ Zebron column (Phenomenex, Torrence CA, USA) and a flame ionization detector with the following oven program: temperature started from $165^{\circ} \mathrm{C}$, held for $3 \mathrm{~min}$, followed by an increase of $1{ }^{\circ} \mathrm{C} / \mathrm{min}$ up to $195^{\circ} \mathrm{C}$, held for $40 \mathrm{~min}$, followed by a second increase of $10^{\circ} \mathrm{C} / \mathrm{min}$ up to $240^{\circ} \mathrm{C}$, and held for $10 \mathrm{~min}$. A constant pressure mode ( $29 \mathrm{psi}$ ) was chosen with hydrogen as the carrier gas. FAMEs were identified by comparison with authentic samples and chromatograms were examined as described previously. Quantitative studies of the performed reactions were done by multiple-points calibration curves of the standard references ( 5 points). The GC peak areas were adjusted using a correction factor obtained by the recovery of the 17:0 methyl ester used as standard.

\subsection{Photolytical Preparation of Mono-Trans CL (MT-CL)}

UV irradiations were performed in a micro photochemical reaction assembly with quartz well (Ace Glass Inc., Vineland, NJ, USA) using a $5.5 \mathrm{~W}$ cold cathode, low pressure, mercury arc, gaseous discharge lamp (corresponds to $\lambda=250-260 \mathrm{~nm}$ ) made of double-bore quartz (Ace Glass Inc., Vineland, $\mathrm{NJ}$, USA). For preparative scope, a higher concentration $(3.5 \mathrm{mM})$ of natural CL is completely dissolved in $\mathrm{MeOH}$. The starting material dissolved in the desired alcohol was added to the photochemical reactor and degassed with $\mathrm{N}_{2}$. While degassing, a solution of 2-mercaptoethanol (0.5 equiv.) was added, calculating the volume of the stock thiol solution in order to reach the desired final CL concentration. The reaction mixture was then degassed for $20 \mathrm{~min}$. After the elapsed time the solution was irradiated with at $250-260 \mathrm{~nm}$ for the indicated times (4 min for the mono-trans CL, see text). Subsequently, the solvent was evaporated under vacuum and the residue was placed under high vacuum for $2 \mathrm{~h}$ to 
completely remove 2-mercaptoethanol. Figure S3 (in Supporting Material) shows the GC analysis showing the formation of mono-trans isomers. The quantity of MT-CL can be calculated from the ${ }^{1} \mathrm{H}$ and ${ }^{13} \mathrm{C}$ NMR spectra as explained in the main text. The assignment of NMR signals to MT-CL and other trans-CL isomers (T-CL) are reported in Figures S6-S9 and discussed with Figure 3 in Section 3.2. Figure S4 shows the four possible structures of MT-CL formed as first products in the isomerization reaction.

a)

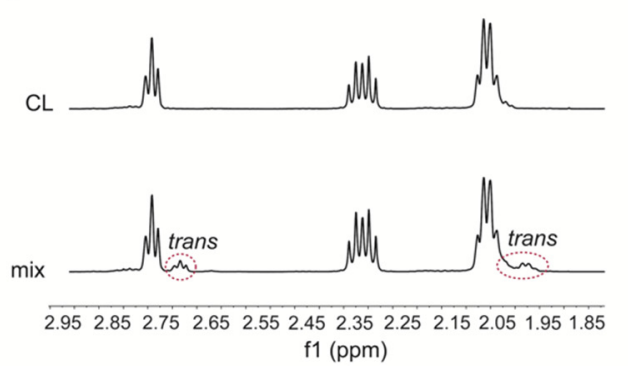

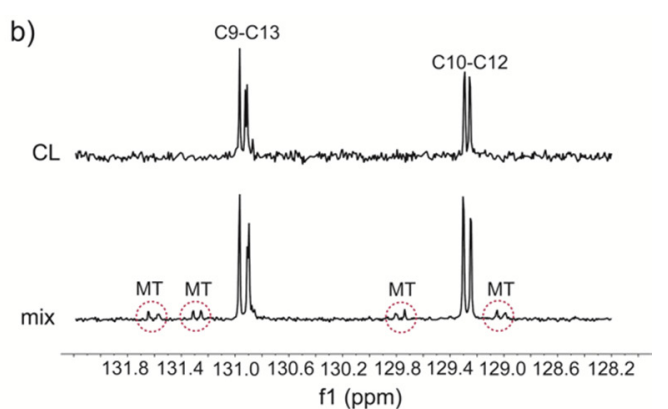

Figure 3. NMR spectral regions of natural cardiolipin $(C L)$ and its reaction crude in the first minutes of UV photolysis containing mono-trans CL (MT-CL, see Figure S4 for the structures): (a) ${ }^{1} \mathrm{H}$ NMR region relative to bis-allylic and allylic proton signals; $(\mathbf{b}){ }^{13} \mathrm{C}$ NMR region relative to alkene carbon atom signals.

\subsection{Preparative Silver-Thin Layer Chromatography (Ag-TLC)}

Preparative TLC glass plates were pre-treated with 5\% $\mathrm{AgNO}_{3}$ solution in acetonitrile for 15 min and then dried at $120{ }^{\circ} \mathrm{C}$ for $1 \mathrm{~h}$ [44]. Eluent for separation: $\mathrm{CHCl}_{3} / \mathrm{MeOH} / \mathrm{H}_{2} \mathrm{O}$ 5: 2: 0.2, $\mathrm{R}_{\mathrm{f}}(\mathrm{CL})=0.52$, $\mathrm{R}_{\mathrm{f}}(\operatorname{mix} \mathrm{MT}-\mathrm{CL})=0.6, \mathrm{R}_{\mathrm{f}}(\mathrm{T}-\mathrm{CL})=0.66$. The desired spots were scratched off, the silica suspended in absolute $\mathrm{EtOH}$ and filtered. Afterwards, the solvent was evaporated under reduced pressure. The Ag-complexes maintained the typical NMR signals with a de-shielding effect due to the presence of metal (see Figures S12 and S13).

\subsection{Preparation of Liposome}

Liposomes were obtained by methanolic injection method [45]. Briefly, $1 \mu \mathrm{mol}$ of phospholipids (POPC or mixture POPC:CL) dissolved in $40 \mu \mathrm{L}$ of methanol were added in one shot to $960 \mu \mathrm{L}$ of $\mathrm{MQ}$ water (conc. $1 \mathrm{mM}$ ) under vigorous stirring with vortex. Stirring was continued at $2200 \mathrm{rpm}$ for $10 \mathrm{~min}$. Then, the suspension was diluted with $1 \mathrm{~mL}$ of water to reach a final lipid concentration of $0.5 \mathrm{mM}$. The characterization of lipid vesicles was performed via DLS.

\section{5. $\gamma$-Radiolysis Experiments}

Irradiations were performed at room temperature $\left(22 \pm 2{ }^{\circ} \mathrm{C}\right)$ using a ${ }^{60} \mathrm{Co}-\mathrm{Gammacell}$ at different dose rates. The exact absorbed radiation dose was determined with the Fricke chemical dosimeter, by taking $G\left(\mathrm{Fe}^{3+}\right)=1.61 \mu \mathrm{mol} \mathrm{J}{ }^{-1}$ [46]. In the radiation experiments, $4 \mathrm{~mL}$ vials equipped with a rubber septum were used. For kinetic experiments, different reactions were prepared from a single stock solution and then each one was stopped at the specific irradiation dose.

A total of $2 \mathrm{~mL}$ of freshly prepared stock solutions $(0.35 \mathrm{mM})$ of CL in $i$-PrOH with 18:1 methyl ester ( 0.33 equiv.) was added together with 2 -mercaptoethanol ( 0.5 equiv.). Afterwards, the solution was degassed with $\mathrm{N}_{2} \mathrm{O}$ for 10 min via a cannula, sealed with parafilm, and irradiated using Gammacell. Transesterification and GC analysis followed the procedure reported above.

A total of $2 \mathrm{~mL}$ of freshly prepared stock solutions $(0.5 \mathrm{mM})$ of POPC/CL liposomes in phosphate-buffered saline MQ water $(\mathrm{pH}=7.4$, POPC/CL ratio 3:1) was added together with 2-mercaptoethanol (1 equiv.). Afterwards, the solution was degassed with $\mathrm{N}_{2} \mathrm{O}$ for 10 min via 
a cannula, sealed with parafilm, and irradiated. After the irradiation time, the reaction mixtures were worked-up following the procedure described below.

\subsection{Lipid Extraction from Liposome Suspensions}

To the liposome suspensions was added 2: 1 chloroform/methanol solution $(5 \times 4 \mathrm{~mL})$, according to the Folch method [47]. The organic layer was collected and dried over anhydrous $\mathrm{Na}_{2} \mathrm{SO}_{4}$, then evaporated under vacuum to dryness. The conversion of the extracted phospholipids to the corresponding FAMEs was performed following the transesterification protocol described above. Incubations were carried out in an incubating orbital shaker (ARGOLAB, SKI 4, Carpi, Italy), keeping the temperature at $37^{\circ} \mathrm{C}$.

Large Unilamellar Vesicles (LUV) were prepared using a mixture of 1-palmitoyl-2-oleoylsn-glycero-phosphatidylcholine (POPC) with bovine hearth CL (stock solution $100 \mathrm{mM}$, ratio 3: 1). LUV stock suspensions were stored at $4{ }^{\circ} \mathrm{C}$ before use. Stock solutions of aqueous $\mathrm{Fe}^{2+}(1 \mathrm{mM})$, $\mathrm{H}_{2} \mathrm{O}_{2}(1 \mathrm{mM})$, 2-mercaptoethanol $(1 \mathrm{mM})$, and buffered $\mathrm{pH} 7.4 \mathrm{Na}_{2} \mathrm{~S}(1 \mathrm{mM}, \mathrm{pH}=7.4)$ were freshly prepared before the liposome experiments. To a $2 \mathrm{~mL}$ vial were added in sequence: (a) Fe( $\left.\mathrm{NH}_{4}\right)_{2}\left(\mathrm{SO}_{4}\right)_{2}$ $\times 6 \mathrm{H}_{2} \mathrm{O}(10 \mu \mathrm{M}), \mathrm{H}_{2} \mathrm{O}_{2}(100 \mu \mathrm{M})$ liposome $(1 \mathrm{mM}) ;(\mathrm{b}) \mathrm{Fe}\left(\mathrm{NH}_{4}\right)_{2}\left(\mathrm{SO}_{4}\right)_{2} \times 6 \mathrm{H}_{2} \mathrm{O}(10 \mu \mathrm{M}), \mathrm{H}_{2} \mathrm{O}_{2}(100 \mu \mathrm{M})$, thiol $(10$ or $100 \mu \mathrm{M})$, liposome $(1 \mathrm{mM})$. A final reaction volume of $1.6 \mathrm{~mL}$ was reached. The reactions were performed by incubation at $37^{\circ} \mathrm{C}$ for $15 \mathrm{~h}$ followed by work-up as described above (extraction, transesterification and GC analysis).

\subsection{Incubation Experiments under Oxidative Conditions}

Incubations were carried out in an incubating orbital shaker (ARGOLAB, SKI 4, Carpi, Italy), keeping the temperature at $37^{\circ} \mathrm{C}$. Large Unilamellar Vesicles (LUV) were prepared using a mixture of POPC with bovine hearth CL (stock solution $100 \mathrm{mM}$, ratio 3: 1). LUV stock suspensions were stored at $4{ }^{\circ} \mathrm{C}$ before the use. Stock solutions of aqueous $\mathrm{Fe}^{2+}(1 \mathrm{mM}), \mathrm{H}_{2} \mathrm{O}_{2}(1 \mathrm{mM})$, 2-mercaptoethanol $(1 \mathrm{mM})$, and buffered $\mathrm{pH} 7.4 \mathrm{Na}_{2} \mathrm{~S}(1 \mathrm{mM}, \mathrm{pH}=7.4)$ were freshly prepared before the liposome experiments. To a $2 \mathrm{~mL}$ vial, the following reagents were added in sequence: $\mathrm{Fe}\left(\mathrm{NH}_{4}\right)_{2}\left(\mathrm{SO}_{4}\right)_{2} \times 6 \mathrm{H}_{2} \mathrm{O}$ $(10 \mu \mathrm{M}), \mathrm{H}_{2} \mathrm{O}_{2}(100 \mu \mathrm{M})$ liposome $(1 \mathrm{mM})$; in the presence of thiol the reagents added in sequqnce were: $\mathrm{Fe}\left(\mathrm{NH}_{4}\right)_{2}\left(\mathrm{SO}_{4}\right)_{2} \times 6 \mathrm{H}_{2} \mathrm{O}(10 \mu \mathrm{M}), \mathrm{H}_{2} \mathrm{O}_{2}(100 \mu \mathrm{M})$, thiol $(10$ or $100 \mu \mathrm{M})$, liposome $(1 \mathrm{mM})$. In both cases, a final reaction volume of $1.6 \mathrm{~mL}$ was reached. The reactions were performed by incubation at $37^{\circ} \mathrm{C}$ for $15 \mathrm{~h}$ followed by work-up as described above (Sections 2.1 and 2.6).

\section{Results and Discussion}

\subsection{Analytical Protocol}

Before carrying out the CL isomerization, we examined the transesterification protocol to analyze the FA residues of CL. Either methanolic $\mathrm{HCl}$ or methanolic $\mathrm{KOH}$ conditions are reported for the lipid transesterification into the corresponding FAME, followed by GC analysis [21-24]. However, in our hands, the methanolic $\mathrm{HCl}$ procedure [21] gave non-reproducible and inconsistent results for $\mathrm{CL}$, due to the decomposition of the starting material. The methanolic $\mathrm{KOH}$ procedure, tested at various $\mathrm{KOH}$ concentrations, also gave poor results related to the yields, as demonstrated by quantitative evaluation using GC calibration and FA standard references (see Table S1 in Supporting Material). In this case, the yield was affected by the hydrolysis of CL to the corresponding free fatty acids, which was never reported with other lipids, such as phosphatidylcholines (PC), under the same conditions [18,48]. As matter of facts, mono-lyso cardiolipins and lyso cardiolipins having 3 and 2 FA chains, respectively, were detected by TLC analysis (see TLC conditions in Supporting Material). The yield of the transesterification step became quantitative when strict anhydrous conditions were realized by methanolic NaOMe solution as reagent (prepared as detailed in Supporting Material), followed by extraction with $n$-hexane and the removal of the solvent under reduced pressure. The optimization of the reaction conditions resulted in the protocol of $22 \mathrm{mM} \mathrm{NaOMe}$ in $\mathrm{MeOH}$ and 
$2 \mathrm{~h}$ of magnetic stirring, in a close vessel or under a nitrogen atmosphere, at room temperature (entry 8, Table S2). Moreover, work-up requires accuracy. In fact, under the NaOMe reaction conditions, inconsistent results were obtained if work-up is performed by simple evaporation of the methanol under vacuum and dissolving the residue in hexane for GC analysis. We also highlighted the use of standard references to check the yields of this analytical protocol at two levels: $(i)$ before the extraction step, by the addition of a stock solution of 17:0 methyl ester to the reaction mixture, used as internal standard for the extraction recovery yield and the FAME yields via multiple-points GC calibration curves; (ii) by the addition of a stock solution of 19:0 methyl ester as internal standard before performing the transesterification reaction, in order to check if the CL hydrolysis occurs directly on the phospholipid substrate or on the forming methyl esters. The complete recovery of 19:0 methyl ester confirmed that hydrolysis does not occur during our transesterification conditions.

Since cardiolipins are normally present in 20-25\% of the total IMM lipids together with other phospholipids, we also tested the optimized method for CL to obtain the simultaneous transformation of a representative phospholipid, POPC, whose transesterification is reported by methanolic $\mathrm{KOH}[18,48]$. Indeed, both lipid classes are effectively transformed into the corresponding FAMEs; therefore, the NaOMe method can be suggested when analysis of biological lipid mixtures is required (see Table S3).

\subsection{MT-CL and T-CL Preparation by UV Photolysis}

Based on our previous extensive work in thiyl radical-catalyzed cis-trans-isomerization of lipid double bonds $[2,16,19,48]$, we proceeded with the isomerization of natural CL by direct photolysis using 2-mercaptoethanol in $\mathrm{MeOH}$, a solvent where CL is perfectly soluble at high concentrations (3.5 $\mathrm{mM})$. The UV-vis absorption spectrum of CL is comparable with methyl linoleate, i.e., both spectra do not show significant absorbance at the wavelength used in the photolysis experiments $(\lambda=250-260 \mathrm{~nm})$. $\mathrm{N}_{2}$-saturated $\mathrm{MeOH}$ solution of bovine heart CL $(3.5 \mathrm{mM})$ was irradiated in a micro-photochemical reactor equipped with a high-pressure $\operatorname{Hg} \operatorname{lamp}(\lambda=250-260 \mathrm{~nm})$ and thiyl radicals are formed according to reactions $1-3$ thus starting the CL double bond transformations as shown in Figure $2 b$.

$$
\begin{gathered}
\mathrm{RSH}+h v \rightarrow \mathrm{RS}^{\bullet}+\mathrm{H}^{\bullet} \\
\mathrm{H}^{\bullet}+\mathrm{CH}_{3} \mathrm{OH} \rightarrow \mathrm{HOCH}_{2}{ }^{\bullet}+\mathrm{H}_{2} \\
\mathrm{HOCH}_{2}^{\bullet}+\mathrm{RSH} \rightarrow \mathrm{RS}^{\bullet}+\mathrm{CH}_{3} \mathrm{OH}
\end{gathered}
$$

In the first minutes, $(4 \mathrm{~min})$ the formation of mono-trans isomers was exclusively obtained and monitored by Ag-TLC, NMR and GC analyses (see Supporting Material). The presence of 9trans,12cis-18:2 ( $\left.\mathbf{L}_{\mathrm{EZ}}\right)$ and 9cis,12trans-18:2 ( $\left.\mathbf{L}_{\mathrm{ZE}}\right)$ moieties in the CL structure is confirmed by GC analysis of the corresponding FAME, using the above described transesterification conditions and known analytical method for isomer separation (Figure S3) [17,18]. The isomerization reaction occurs step-by-step, as shown in Figure 2, i.e., randomly on one of the four fatty acid chains, and the first formed products are likely those containing one trans double bond in one of the linoleoyl chains (Figure S4) shows the four MT-CL structures that can be formed. Another feature of the cis-trans isomerization is that a catalytic amount of thiol can do it, due to the radical chain process that has been fully characterized on linoleoyl residues in previous work [18,19]. In Section 3.4, more details of kinetics will be reported. A non-destructive estimation of the mono-trans CL yield can be obtained using NMR (nuclear magnetic resonance). Figure 3 shows the relevant regions of ${ }^{1} \mathrm{H}$ (Figure $3 a$ ) and ${ }^{13} \mathrm{C}$ (Figure $3 b$ ) NMR spectra (full spectra in Figures S1 and S2 for CL and Figures S5-S9 for the CL isomer mix in Supporting Material), registered directly on the crude reaction mixture, before transesterification, obtained by evaporating the solvent under reduced pressure and keeping the residue at high vacuum for $2 \mathrm{~h}$ to remove residual $\mathrm{HO}\left(\mathrm{CH}_{2}\right)_{2} \mathrm{SH}$. The crude was dissolved in the deuterated solvent for the analysis. In Figure 3a, the comparison between the ${ }^{1} \mathrm{H}$ NMR spectra of natural CL (containing only $\mathbf{L}_{\mathbf{Z Z}}$ residues) and the corresponding reaction mix evidences the triplet of the bis-allylic protons 
at $2.72 \mathrm{ppm}$ and the multiplet of the allylic protons at $1.99 \mathrm{ppm}$ corresponding to the mono-trans structures [19,49]. From the integration of the bisallylic and allylic hydrogen signals, a cis/trans isomer ratio of ca. 6: 1 is envisaged (Figure S6). Taking into account that in the CL isomer structures the trans double-bond-containing chain is present together with the other three cis double-bond-containing chains, under our experimental conditions, the mono-trans CL isomers are formed in ca. $46 \%$ yield. An interesting observation came from the ${ }^{13} \mathrm{C}$ NMR spectra shown in Figure $3 b$, focusing on the double bond region. The alkenyl carbon atoms of the natural CL, taking into account previously reported data despite being reported in $\mathrm{CDCl}_{3}[19,49]$, are assigned to the $\mathrm{C} 9-\mathrm{C} 13$ carbon atom resonances at a lower field than the $\mathrm{C} 10-\mathrm{C} 12$ carbon atom resonances. For 9cis,12trans-18: 2, the literature reported a 0.7 ppm more de-shielded resonance than in the cis isomer [49]; therefore, we can attribute the peak at 131.7 ppm to the C-13 of the 9cis,12trans-18: 2 -containing CL (see Figure S6 for details). By analogy with the CL structure, the signal at 131.6 ppm can be attributed to C-9 in the same molecule. The alkenyl resonances of the other three fatty acid chains of this mono-trans CL likely remain in the same positions than in the natural cis CL. Examining the resonances at 131.3 and 131.2 ppm again, it is possible to attribute to C-9 and C-13 of a second mono-trans CL isomer, by analogy with the 9trans,12cis-18:2 literature data [49]. For the signals at 129.7 and 129.6, 128.8 and 128.7 ppm, the less de-shielded peak at 128.7 ppm is attributed to C-10 of the 9trans,12cis-18:2 followed by the C-12 at 128.8 ppm in the same chain, whereas the resonances at 129.7 and $129.6 \mathrm{ppm}$ individuate the 9cis,12trans-18:2 CL isomer. It is worth noting that another interesting signature of mono-trans CL isomers is the 5 ppm shift of the C-11 (bisallylic) carbon atom, going from 26.04 ppm to $33.61 \mathrm{ppm}$, as it is known for linoleic acid isomers (Figure S7) [49]. The CL molecule being with a symmetry plane, it is likely that the four mono-trans CL isomers, presenting a 9-trans or a 12-trans double bond in one chain, cannot be distinguished based on whether the trans double-bond-containing chain residue is in an external or internal position with respect to the plane (cf. Figure S4). Overall, the new clearly distinguishable signatures of the ${ }^{13} \mathrm{C} \mathrm{NMR}$ spectrum represent a milestone, in view of the use of NMR in the "omics" platforms proposed for biological samples.

The GC analysis of the FA residues after 4 min photolysis evidenced the $\mathbf{L}_{\mathbf{Z Z}}: \mathbf{L}_{\mathbf{E Z}}: \mathbf{L}_{\mathbf{Z E}}: \mathbf{L}_{\mathbf{E E}}$ ratio to be 84:7.6:7.6:0.8 (see Figures S3-S9). We continued the CL isomerization under photolytic conditions up to $30 \mathrm{~min}$, performing the NMR of the crude (see Figure S10) and the transesterification procedures as described above. We determined the T-CL yield and the isomers' ratio of $\mathbf{L}_{\mathbf{Z Z}}: \mathbf{L}_{\mathbf{E Z}}: \mathbf{L}_{\mathbf{Z E}}: \mathbf{L}_{\mathbf{E E}}=5: 13: 13: 69$, which did not change, representing the thermodynamic equilibrium, i.e., the level of isomerization that remains constant over time. It is interesting to observe that, for the analogous isomerization of methyl linoleate, the ratio $\mathbf{L}_{\mathbf{Z Z}}: \mathbf{L}_{\mathbf{E Z}}: \mathbf{L}_{\mathbf{Z E}}: \mathbf{L}_{\mathbf{E E}}=4: 13: 13: 70$ was determined at thermodynamic equilibrium [19].

\subsection{Isolation of MT-CL and T-CL as Ag-complexes}

Afterwards, we focused on the separation of the trans CL isomers from the reaction crude. The crude mixtures at 4 and 20 min of photolysis were purified employing preparative TLC plates pre-treated with $5 \% \mathrm{AgNO}_{3}$ solution in acetonitrile, with a previously reported protocol (Ag-TLC) [44]. The desired spots were scratched off and the silica was suspended in absolute EtOH and filtered, thus affording the ethanolic extract. After evaporation under reduced pressure, white solids containing the Ag-complexes of $\mathbf{L}_{\mathbf{E Z}}+\mathbf{L}_{\mathbf{Z E}} \mathrm{CL}$ and $\mathbf{L}_{\mathbf{E E}} \mathrm{CL}$ were obtained. We also prepared the Ag-complex of the natural CL as reference. In Figures S12 and S13 of Supporting Material, the NMR spectra of the Ag-complexes of CL and T-CL are shown, where it is possible to appreciate the de-shielding of allylic, bis-allylic and alkenyl protons as an effect of the metal complexation of the phospholipid structures. We proceeded with the decomplexation step using saturated $\mathrm{NaCl}$ aqueous solution and the forming of an $\mathrm{AgCl}$ precipitate. After the lyophilization of this residue treatment with absolute ethanol and filtration, the natural CL and MT-CL isomers were obtained as $\mathrm{Na}^{+}$salt. We observed that the stability of the salt was greatly reduced and the isolated materials were labile. Work is ongoing in our laboratory to have a satisfactory isolation procedure for CL isomers. For the first time, a mix of MT-CL/CL and $\mathrm{T}-\mathrm{CL} / \mathrm{CL}$ can be obtained, knowing the quantity of isomers in the mix, and these modified biomolecules 
can be used for further studies, as, in our case, we used it to understand the effects on membrane formation, as reported in Section 3.5.

\subsection{Kinetic and Product Studies by $\gamma$-Radiolysis of CL}

Thiyl radicals were produced by $\gamma$-radiolysis of $\mathrm{N}_{2} \mathrm{O}$-saturated $i$-PrOH solutions containing CL $(0.35 \mathrm{mM})$ and 2 -mercaptoethanol (0.5 equiv.) in the presence of 0.33 equiv. of methyl oleate acting as an internal reference for the isomerization yield. Radiolysis of $i$ - $\mathrm{PrOH}$ led mainly to solvated electrons $\mathrm{e}_{\mathrm{sol}}{ }^{-}$and alkyl radicals, as shown in Reaction 4. In the $\mathrm{N}_{2} \mathrm{O}$-saturated solution, $\mathrm{e}_{\text {sol }}{ }^{-}$were efficiently quenched to form $\mathrm{N}_{2}$ and $\mathrm{O}^{\bullet-}$ radical anion (Reaction 5), which could react directly with the solvent to generate $\left(\mathrm{CH}_{3}\right)_{2} \mathrm{C}\left({ }^{\bullet}\right) \mathrm{OH}$ (Reaction $\left.6, k=1.9 \times 10^{9} \mathrm{M}^{-1} \mathrm{~s}^{-1}\right)[50,51]$. Then, the alkyl radicals $\left(\mathrm{R}=\mathrm{CH}_{3}{ }^{\bullet}\right.$ and $\left.\left(\mathrm{CH}_{3}\right)_{2} \mathrm{C}\left({ }^{\bullet}\right) \mathrm{OH}\right)$ reacted with 2-mercaptoethanol to produce thiyl radicals (Reaction 7).

$$
\begin{gathered}
i-\mathrm{PrOH}+\gamma \text {-irr } \rightarrow\left(\mathrm{CH}_{3}\right)_{2} \mathrm{C}\left({ }^{\bullet}\right) \mathrm{OH}+\mathrm{e}_{\mathrm{sol}}{ }^{-}+\mathrm{CH}_{3}^{\bullet} \\
\mathrm{e}_{\mathrm{sol}}{ }^{-}+\mathrm{N}_{2} \mathrm{O} \rightarrow \mathrm{N}_{2}+\mathrm{O}^{\bullet-} \\
\mathrm{O}^{\bullet-}+i-\mathrm{PrOH} \rightarrow\left(\mathrm{CH}_{3}\right)_{2} \mathrm{C}\left({ }^{\bullet}\right) \mathrm{OH}+\mathrm{HO}^{-} \\
\mathrm{R}^{\bullet}+\mathrm{HO}\left(\mathrm{CH}_{2}\right)_{2} \mathrm{SH} \rightarrow \mathrm{RH}+\mathrm{HO}\left(\mathrm{CH}_{2}\right)_{2} \mathrm{~S}^{\bullet}
\end{gathered}
$$

We investigated the reaction by detailed products study and dose-dependent experiments, irradiating five samples (0.35 mM CL each) for $100 \mathrm{~Gy}$ dose intervals, until reaching the total dose of $400 \mathrm{~Gy}$ in the last sample. The reaction mixtures were worked-up and analyzed as described in Supporting Material. The results shown in Table 1 depict the extent of the isomerization of the two major unsaturated fatty acid residues from CL (linoleic and vaccenic acids), and the addition of methyl oleate $(0.33 \mathrm{mM})$ was used as an internal reference for the isomerization course. Figures S14 and S15 shows the corresponding graphs of the reaction course. While the isomerization of the vaccenic residue and methyl oleate proceeded proportionally to the dose course, the extent of the isomerization of linoleic acid residues showed a more complex pattern. Initially, the step-by-step isomerization process generated the two mono-trans isomers with the same percentages (100 Gy, 13\% each in Table 1).

\begin{tabular}{|c|c|c|c|c|c|c|c|c|}
\hline \multirow{2}{*}{ Dose, Gy } & \multicolumn{2}{|c|}{ Internal Control ( $\%$ rel) ${ }^{1,2}$} & \multicolumn{6}{|c|}{ CL Fatty Acid Residues (\% rel) ${ }^{2}$} \\
\hline & 9 cis-18:1 & 9trans-18:1 & 11cis-18:1 & 11trans-18:1 & $\mathrm{L}_{\mathrm{ZZ}}$ & $\mathrm{L}_{\mathrm{EZ}}$ & $\mathbf{L}_{\mathbf{Z E}}$ & $\mathbf{L}_{\mathrm{EE}}$ \\
\hline 0 & 100 & 0 & 100 & 0 & 100 & 0 & 0 & 0 \\
\hline 100 & 84.4 & 15.6 & 83.7 & 12.3 & 71.3 & 13.0 & 13.0 & 2.7 \\
\hline 200 & 67.2 & 32.8 & 64.9 & 35.1 & 44.9 & 21.2 & 21.2 & 12.7 \\
\hline 300 & 53.4 & 46.6 & 55.6 & 44.4 & 33.8 & 22.1 & 22.2 & 21.9 \\
\hline 400 & 40.5 & 59.5 & 44.9 & 55.1 & 24.6 & 21.4 & 21.2 & 32.8 \\
\hline
\end{tabular}
Proceeding with the dose, the levels of the mono-trans remained constant at values of ca. $22 \%$, while the formation of $\mathrm{L}_{\mathrm{EE}}$ increased gradually, achieving $32.8 \%$ at $400 \mathrm{~Gy}$ dose.

Table 1. $\gamma$-Radiolysis of $\mathrm{CL}(0.35 \mathrm{mM})$ and $\mathrm{HO}\left(\mathrm{CH}_{2}\right)_{2} \mathrm{SH}(0.5$ equiv. $)$ in $\mathrm{N}_{2} \mathrm{O}$-saturated $i$-PrOH at $22{ }^{\circ} \mathrm{C}$.

${ }^{1}$ Methyl oleate (9cis-18:1; 0.33 equiv.) as internal standard. ${ }^{2}$ After the transesterification of reaction crudes (yields > $95 \%$ ), the ratios of geometrical isomers were determined by GC analysis as relative percentages (\% rel) of isomers, calculated separately for the two 18:1 and 18:2 residues of CL.

Figure 4 displays the reaction course for the isomer concentrations as a function of irradiation dose for $0.35 \mathrm{mM}$ of $\mathrm{CL}$, which corresponds to $1.40 \mathrm{mM}$ of $\mathrm{L}_{\mathbf{Z Z}}$ residues, and 0.5 equiv. $\mathrm{HO}\left(\mathrm{CH}_{2}\right)_{2} \mathrm{SH}$. The diminution of $\mathbf{L z z}$ matched with the formation of mono-trans and di-trans isomers $\left(\mathbf{L}_{\mathbf{Z E}}, \mathbf{L}_{\mathrm{EZ}}\right.$, and $\left.\mathbf{L}_{\mathrm{EE}}\right)$. The two mono-trans isomers were found in equal amounts and are reported together in Figure 4. However, the sum of all geometrical isomers (total $\mathbf{L}$ ) proportionally decreased by increasing the dose (ca. 20\%), indicating secondary products formation to account for the full mass balance. It is gratifying to see the similarity of this figure with the analogous radiolysis experiment of 
methyl linoleate [19]. The diminution of total $\mathbf{L}$ can be probably attributed to hydrogen abstraction from the bis-allylic position by thiyl radicals and adduct formation with thiol, as previously established for methyl linoleate [19].

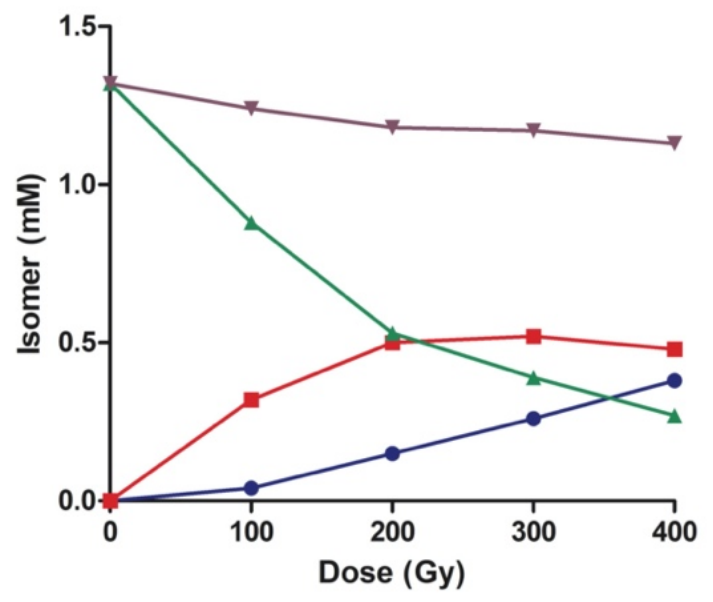

Figure 4. Dose profile of cis-trans isomerization of linoleoyl residue (Lzz corresponding to $1.32 \mathrm{mM}$ ) of $\mathrm{CL}(0.35 \mathrm{mM})$ catalyzed by thiyl radicals generated by $\gamma$-radiolysis of $\mathrm{HO}\left(\mathrm{CH}_{2}\right)_{2} \mathrm{SH}(0.5$ equiv. $)$ in the presence of 0.33 equiv. of methyl oleate as control in $\mathrm{N}_{2} \mathrm{O}$-saturated $i$-PrOH at $22^{\circ} \mathrm{C}$. Profiles of $\mathbf{L z z}_{z Z}$ (green $\Delta$ ), $\mathbf{L}_{\mathbf{Z E}}+\mathbf{L}_{\mathbf{E Z}}\left(\right.$ red $\mathbf{n}$ ) and $\mathbf{L}_{\mathbf{E E}}($ blue $\bullet$ ), and the sum of all geometrical isomers (purple $\mathbf{v}$ ).

The disappearance of the starting material $(\mathrm{mol} \mathrm{kg}-1)$ divided by the absorbed dose $\left(1 \mathrm{~Gy}=1 \mathrm{~J} \mathrm{~kg}^{-1}\right)$ gives the radiation chemical yield $(G)$ or $G\left(-\mathbf{L}_{\mathrm{ZZ}}\right)$. The extrapolation to zero dose gives $\mathrm{G}=5.06 \mu \mathrm{mol} \mathrm{J}{ }^{-1}$ (see Figure S15B). Assuming that the $G\left(\mathrm{RS}^{\bullet}\right)$ is $0.65 \mu \mathrm{mol} \mathrm{J}{ }^{-1}$, we calculated the catalytic cycle to be 8 at the initial phase. For the analogous isomerization of $4.7 \mathrm{mM}$ methyl linoleate and $20 \mathrm{mM} \mathrm{HO}\left(\mathrm{CH}_{2}\right)_{2} \mathrm{SH}$, a catalytic cycle of 13 was calculated [19].

\subsection{Large Unilamellar Vesicles (LUV) Containing CL, MT-CL and T-CL}

Next, we examined the behavior of cardiolipins in the supramolecular organization of LUV [48]. Biomimetic models of LUV containing 3: 1 POPC:CL (the cardiolipin percentage typically present in IMM) were prepared using POPC in a 3: 1 mixture with MT-CL or T-CL (obtained, as above described, after $4 \mathrm{~min}$ and $20 \mathrm{~min}$ photolysis of $\mathrm{CL}$, respectively). LUV were obtained by the methanolic injection method [45] (as described in Supporting Material). The characterization of the resulting LUVs was performed via dynamic light scattering (DLS), and the average diameters are summarized in Table 2, in comparison with liposomes prepared only with POPC. The presence of CL resulted in an increase in the hydrodynamic diameter from 93.2 to $198 \mathrm{~nm}$ (entry 2, Table 2); it is interesting to see that, using lipid mixtures containing MT-CL/CL and T-CL/CL, a contraction of the vesicle diameter of ca $16 \%$ and $26 \%$, respectively, was observed (cf. entries 3 and 4, Table 2). This result evidences that the geometrical trans isomer CL structure determines a tighter packing of the lipid layer than the cis one, affording a decrease in the vesicle size. This effect of reduced diameter, due to the different arrangement of trans fatty acid residues, was previously observed in phospholipid vesicles containing the 9trans-18:1 moiety [33].

With the cardiolipin-containing liposomes in our hands, we progressed our investigation on their reactivity with thiyl radicals generated by either by $\gamma$-radiolysis or Fenton-type reaction in aqueous solution. 
Table 2. Dynamic light scattering (DLS) analysis of liposomes $(1 \mathrm{mM})$ in phosphate-buffered water $(\mathrm{pH}=7.4)$ of different 1-palmitoyl-2-oleoyl phosphatidylcholine (POPC) and CL compositions.

\begin{tabular}{ccccc}
\hline Entry & Phospholipid $^{\mathbf{1}}$ & Ratio & Diameter, $^{\text {nm }}$ & Polydispersity \\
\hline 1 & POPC & - & 93.2 & 0.211 \\
2 & POPC/CL & $3: 1$ & 198 & 0.278 \\
3 & POPC/MT-CL $^{2}$ & $3: 1$ & 167 & 0.151 \\
4 & POPC/T-CL $^{3}$ & $3: 1$ & 146.1 & 0.394 \\
\hline
\end{tabular}

${ }^{1} 1 \mathrm{mM} ;{ }^{2}$ MT-CL obtained after 4 min photolysis of CL. ${ }^{3}$ T-CL obtained after 20 min photolysis of CL.

\section{6. $\gamma$-Radiolysis of CL-Containing Liposomes}

The radiolysis of neutral water leads mainly to the reactive species $\mathrm{e}_{\mathrm{aq}}{ }^{-}, \mathrm{HO}^{\bullet}$, and $\mathrm{H}^{\bullet}$, together with $\mathrm{H}^{+}$and $\mathrm{H}_{2} \mathrm{O}_{2}$, as shown in Reaction 8 . The values in brackets represent the radiation chemical

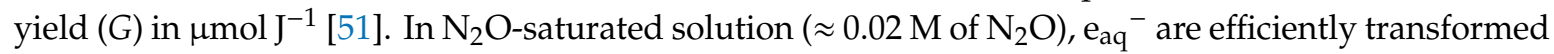
into $\mathrm{HO}^{\bullet}$ radicals via Reaction $9\left(k=9.1 \times 10^{9} \mathrm{M}^{-1} \mathrm{~s}^{-1}\right)$, affording $\mathrm{G}\left(\mathrm{HO}^{\bullet}\right)=0.55 \mu \mathrm{mol} \mathrm{J}^{-1}$; that is, $\mathrm{HO}^{\bullet}$ and $\mathrm{H}^{\bullet}$ account for $90 \%$ and $10 \%$, respectively, of the reactive species. Subsequently, $\mathrm{HO}^{\bullet}$ and $\mathrm{H}^{\bullet}$ atoms react with RSH, affording the desired thiyl radicals (Reactions 10 and $11, k=6.8 \times 10^{9} \mathrm{M}^{-1} \mathrm{~s}^{-1}$ and $k=1.7 \times 10^{9} \mathrm{M}^{-1} \mathrm{~s}^{-1}$, respectively) [50,51].

$$
\begin{gathered}
\mathrm{H}_{2} \mathrm{O}+\gamma \text {-irr } \rightarrow \mathrm{eaq}^{-}{ }^{-}(0.27), \mathrm{HO}^{\bullet}(0.28), \mathrm{H}^{\bullet}(0.06) \\
\mathrm{e}_{\mathrm{aq}}{ }^{-}+\mathrm{N}_{2} \mathrm{O}+\mathrm{H}_{2} \mathrm{O} \rightarrow \mathrm{HO}^{\bullet}+\mathrm{N}_{2}+\mathrm{HO}^{-} \\
\mathrm{HO}^{\bullet}+\mathrm{RSH} \rightarrow \mathrm{H}_{2} \mathrm{O}+\mathrm{RS}^{\bullet} \\
\mathrm{H}^{\bullet}+\mathrm{RSH} \rightarrow \mathrm{H}_{2}+\mathrm{RS}^{\bullet}
\end{gathered}
$$

Five independent liposome samples, containing 3: $1 \mathrm{POPC} / \mathrm{CL}$, in water $(0.5 \mathrm{mM})$, in the presence of $0.5 \mathrm{mM} \mathrm{HO}\left(\mathrm{CH}_{2}\right)_{2} \mathrm{SH}$, were used in a dose-dependent experiment. The amount of thiol was 3.3-fold higher than in solution in order to properly evaluate the reactivity of linoleic acid residues. Each sample was stopped after 100 Gy dose intervals until reaching a total dose of 400 Gy (Table 3, see also Figure S16). The isomerization of vaccenic and oleic acid moieties proceeded proportionally to the dose course, similar to the above-described isomerization in $i-\mathrm{PrOH}$ solutions. Looking at the 100 Gy dose experiment, the outcome clearly highlighted a different reactivity of $\mathbf{L}_{\mathbf{Z Z}}$ residues in liposomal organization. Interestingly, while in solution, the two mono-trans isomers were generated at the same extent (cf., Table 1); in this case, we observed that the preferential formation of $\mathbf{L}_{\mathrm{EZ}}$, ca. was $6 \%$ higher than $\mathbf{L}_{\mathrm{ZE}}$. The formation of di-trans linoleate residues $\left(\mathrm{L}_{\mathrm{EE}}\right)$ reached $11.3 \%, 5$ times higher than the corresponding time point in the previous experiment in solution. Subsequently, at $200 \mathrm{~Gy}$, the levels of $\mathbf{L}_{\mathrm{EZ}}$ and $\mathbf{L}_{\mathrm{ZE}}$ reached a plateau at ca. 18 and 11\%, respectively, and remained constant, while the amount of $\mathbf{L}_{E E}$ increases progressively. Figure 4 shows the concentration of each isomer $(\mathrm{mM})$ as a function of the irradiation dose, including the total $\mathbf{L}$ (the sum of all geometrical isomers). The different amounts of mono-trans isomers and di-trans isomers in the liposome experiment are explained by the diffusion of the amphiphilic $\mathrm{HOCH}_{2} \mathrm{CH}_{2} \mathrm{~S}^{\bullet}$ radical into the membrane assembly, and the supramolecular organization of the lipid bilayer. In fact, this radical freely diffuses between aqueous and lipid compartments and, when it goes through the hydrophobic region of the membrane bilayer, the double bonds of the CL structures closest to the glycerol moiety are the first to be reached and react. Therefore, the reactivity outcome is driven by both the supramolecular arrangement of the hydrocarbon tails and the highly defined lateral diffusion. Due to the packing of fatty acid residues and, consequently, to a highly defined lateral diffusion, thiyl radicals, after the isomerization of the 9,10-double bond, have a chance to isomerize the second double bond in the same chain before migrating laterally. The present results are in accordance with the previously reported PUFA reactivity 
of, e.g., linoleic and arachidonic acids [2,48]. This "positional effect" can be investigated in further work on the endogenous formation of trans lipids in mitochondrial membranes.

Table 3. $\gamma$-Radiolysis of POPC/CL liposomes $(0.5 \mathrm{mM})$ in $\mathrm{N}_{2} \mathrm{O}$-saturated phosphate-buffered water $(\mathrm{pH}=7.4)$ and $\mathrm{HO}\left(\mathrm{CH}_{2}\right)_{2} \mathrm{SH}$ (1 equiv.) at $22{ }^{\circ} \mathrm{C}$.

\begin{tabular}{|c|c|c|c|c|c|c|c|c|}
\hline \multirow{2}{*}{ Dose, Gy } & \multicolumn{2}{|c|}{ 18: 1 from POPC (\% rel) ${ }^{1}$} & \multicolumn{6}{|c|}{ CL fatty acid residues (\% rel) ${ }^{1}$} \\
\hline & 9 cis-18:1 & 9trans-18:1 & 11cis-18:1 & 11trans-18:1 & $\mathbf{L}_{\mathbf{Z Z}}$ & $\mathbf{L}_{\mathrm{EZ}}$ & $\mathbf{L}_{\text {ZE }}$ & $\mathbf{L}_{\mathrm{EE}}$ \\
\hline 0 & 100 & 0 & 100 & 0 & 100 & 0 & 0 & 0 \\
\hline 100 & 65.4 & 34.6 & 70.9 & 29.1 & 65.3 & 14.6 & 8.8 & 11.3 \\
\hline 200 & 50.7 & 49.3 & 56.2 & 43.8 & 51.4 & 17.8 & 10.7 & 20.1 \\
\hline 300 & 38.8 & 61.2 & 49.2 & 50.8 & 44.5 & 18.5 & 11.5 & 25.5 \\
\hline 400 & 34.6 & 65.4 & 43.0 & 57.0 & 44.2 & 17.9 & 11.1 & 26.8 \\
\hline
\end{tabular}

${ }^{1}$ After the transesterification of reaction crudes (yields $>95 \%$ ), the geometrical isomers ratios were determined by GC analysis as relative percentages (\% rel) of isomers, calculated separately for 18:1 and 18:2 residues.

As depicted in Figure 5, the initial amount of methyl linoleate (purple line) proportionally decreased by increasing dose (ca. 50\%), compared to the experiment in solution, which is larger than the experiment in solution (ca. 20\%) due to the higher amount of thiol used. Although we did not identify products other than geometrical isomers in this experiment, based on our previous publications, the reactivity and products derived from hydrogen abstraction from the bis-allylic position by thiyl radicals and to adducts with thiol are likely to occur [19].

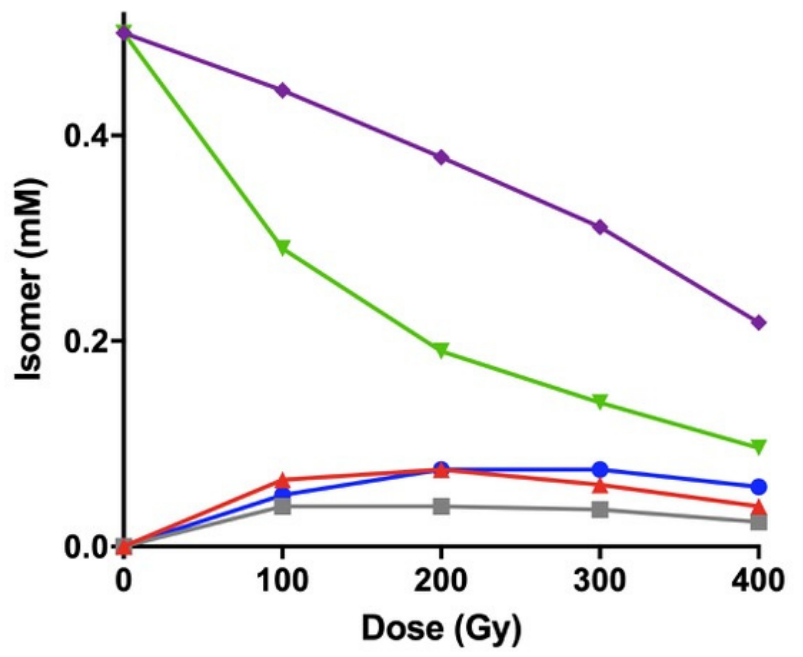

Figure 5. $\gamma$-Radiolysis of $0.5 \mathrm{mM}$ POPC/CL liposomes (3:1) in the presence of $0.5 \mathrm{mM} \mathrm{HO}\left(\mathrm{CH}_{2}\right)_{2} \mathrm{SH}$ as a function of the irradiation dose. The concentration $(\mathrm{mM})$ of $\mathbf{L}_{\mathrm{ZZ}}$ (green $\left.\mathbf{\nabla}\right), \mathbf{L}_{\mathrm{ZE}}$ (grey $\left.\mathbf{\square}\right), \mathbf{L}_{\mathrm{EZ}}(\operatorname{red} \mathbf{\Delta})$ and $\operatorname{LEE}_{\mathrm{EE}}$ (blue $\bullet$ ), and the sum of all geometrical isomers (purple $\downarrow$ ).

Regarding the radiation chemical yield $(G)$, the plots vs. dose is reported in Figure S17A. The extrapolation of $G$ at zero dose gives: $G\left(-L_{\mathrm{ZZ}}\right)=2.4 \mu \mathrm{mol} \mathrm{J}{ }^{-1}, G\left(\mathbf{L}_{\mathrm{EZ}}\right)=0.8 \mu \mathrm{mol} \mathrm{J}{ }^{-1}$, $G\left(\mathbf{L}_{\mathrm{ZE}}\right)=0.5 \mu \mathrm{mol} \mathrm{J}{ }^{-1}$, and $G\left(\mathbf{L}_{\mathrm{EE}}\right)=0.6 \mu \mathrm{mol} \mathrm{J}^{-1}$ (Figure S17B). Assuming that the $G\left(\mathrm{RS}^{\bullet}\right)$ is $0.65 \mu \mathrm{mol} \mathrm{J}^{-1}$, we calculated the catalytic cycle to be 4 at the initial phase. Moreover, the $G$ for the disappearance of the sum of geometrical isomers is $0.6 \mu \mathrm{mol} \mathrm{J}^{-1}$ (Figure S17B), suggesting that each thiyl radical consumes one molecule of $\mathbf{L}_{\mathbf{Z z}}$ or its geometrical isomer.

Additionally, each irradiated solution was analyzed via dynamic light scattering (DLS) prior to the work-up. The measured vesicle diameters are summarized in Table 4. It was gratifying to observe that the size of the lipid vesicles decreased by ca. $10-15 \%$ as long as the cis-trans isomerization proceeds (Table 4). The detected diameters decreased with the progressive double bond isomerization and the amounts of trans-containing fatty acid chains (cf., Table 2). Although this model does not represent the 
lipid diversity of natural mitochondria, it effectively shows the consequences of the trans geometry produced in the structural organization of membranes.

Table 4. DLS analysis of irradiated POPC/CL liposomes $(0.5 \mathrm{mM})$ in phosphate-buffered water $(\mathrm{pH}=7.4)$.

\begin{tabular}{ccc}
\hline Dose, Gy & Diameter, $\mathbf{n m}$ & Polydispersity \\
\hline 0 & 198 & 0.278 \\
100 & 187.4 & 0.310 \\
200 & 184.4 & 0.286 \\
300 & 184 & 0.303 \\
400 & 176.6 & 0.279 \\
\hline
\end{tabular}

\subsection{CL-Containing Liposomes Under Oxidative Conditions.}

In order to assay free radical reactivity leading to cardiolipin isomerization under conditions of oxidative stress [15], experiments were carried out under biologically related conditions, i.e., in the presence of oxygen and under the free radical conditions created by Fenton reagents. A total of $1 \mathrm{mM}$ of aqueous liposome suspension composed of 3: 1 POPC/CL was incubated at $37^{\circ} \mathrm{C}$, without degassing and leaving the vial under air for $15 \mathrm{~h}$ ("open air"), in the absence or presence of thiols, i.e., choosing two different amphiphilic thiols, such as $\mathrm{HO}\left(\mathrm{CH}_{2}\right)_{2} \mathrm{SH}$ and $\mathrm{H}_{2} \mathrm{~S}$. The latter was generated from its sodium salt $\mathrm{Na}_{2} \mathrm{~S}$, used at two different concentrations $(10$ and $100 \mu \mathrm{M})$, and at the same time in the presence of $\mathrm{Fe}^{2+}$ salt and $100 \mu \mathrm{M} \mathrm{H}_{2} \mathrm{O}_{2}$ (see Experimental details as reported in Supporting Material). The reaction of the reduced-state transition metal ions, such as $\mathrm{Fe}^{2+}$, with $\mathrm{H}_{2} \mathrm{O}_{2}$ is known to give $\mathrm{HO}^{\bullet}$ radicals according to the reaction 12 [52,53].

$$
\mathrm{H}_{2} \mathrm{O}_{2}+\mathrm{Fe}^{2+} \rightarrow \mathrm{HO}^{\bullet}+\mathrm{HO}^{-}+\mathrm{Fe}^{3+}
$$

This reaction, referred to as the Fenton reaction, has been reported to be responsible for some of the toxicity associated with $\mathrm{H}_{2} \mathrm{O}_{2}$ in vivo, and is certainly characteristic of the mitochondrial chemistry. The combined presence of thiols maintains iron in the reduced state $\left(\mathrm{Fe}^{2+}\right)$ with the formation of thiyl radical (reaction 13):

$$
\mathrm{RSH}+\mathrm{Fe}^{3+} \rightarrow \mathrm{RS}^{\bullet}+\mathrm{Fe}^{2+}
$$

Both $\mathrm{HO}^{\bullet}$ and $\mathrm{RS}^{\bullet}$ are able to abstract the bisallylic hydrogen from $\mathrm{LH}$ and generate the bisallylic radical in the linoleic residue (reaction 14) that starts the radical chain lipid peroxidation (reactions 15 and 16), whereas the cis-trans isomerization of double bonds of oleic and linoleic acids occurs by RS ${ }^{\bullet}$ radicals $[20,54]$.

$$
\begin{gathered}
\mathrm{HO}^{\bullet} / \mathrm{RS}^{\bullet}+\mathrm{LH} \rightarrow \mathrm{H}_{2} \mathrm{O} / \mathrm{RSH}+\mathrm{L}^{\bullet} \\
\mathrm{L}^{\bullet}+\mathrm{O}_{2} \rightarrow \mathrm{LOO}^{\bullet} \\
\mathrm{LOO}^{\bullet}+\mathrm{LH} \rightarrow \mathrm{LOOH}+\mathrm{L}^{\bullet}
\end{gathered}
$$

The results are shown in Table 5 reporting the transformations of the two main unsaturated fatty acid moieties composing POPC and CL, i.e., oleic acid (9cis-18:1) and linoleic acid (Lzz), respectively, as obtained from triplicates of the reaction under the indicated conditions. The cis-trans isomerization was present with both thiols and at both concentrations, with small variations that are not worth being considered at this point. Without thiol, the isomerization did not occur.

Under incubation without the removal of oxygen and in the presence of Fenton reagent, it can be expected that linoleic acid residue is consumed by oxidative pathways. In our experiments, we did not directly measure the oxidative by-products, but we indirectly evaluated the linoleic acid loss or consumption, by quantifying the remaining linoleic acid residues by calibration and an appropriate internal standard added to the reaction mixture (C17:0). It is interesting to note that, since both oxidation 
and isomerization reactions occur, this means that, under the conditions used, thiol compounds are not able at the concentrations used to protect the unsaturated lipids from oxidative degradation under free radical conditions.

Table 5. POPC/CL liposome (1 mM) Suspension in Phosphate-Buffered Water $(\mathrm{pH}=7.4)$ in the Presence of $10 \mu \mathrm{M} \mathrm{Fe}^{2+}, 100 \mu \mathrm{M} \mathrm{H}_{2} \mathrm{O}_{2}$ and Thiol, Incubated at $37^{\circ} \mathrm{C}$ in Open Air for $15 \mathrm{~h}$.

\begin{tabular}{|c|c|c|c|c|c|}
\hline \multirow{2}{*}{ Thiol, $\mu \mathrm{M}$} & \multicolumn{2}{|c|}{ 18:1 from POPC (\% rel) ${ }^{1}$} & \multicolumn{3}{|c|}{ 18:2 from $C L^{1}$} \\
\hline & 9 cis-18:1 2,3 & 9trans-18:1 ${ }^{2,3}$ & $\mathrm{~L}_{\mathrm{ZZ}}{ }^{3}$ & $\mathrm{~L}_{\mathrm{EZ}}+\mathrm{L}_{\mathrm{ZE}}{ }^{3}$ & Lzz $_{\text {Consumption }}{ }^{3}$ \\
\hline- & 100 & - & $14.5 \pm 0.9$ & - & $85.0 \pm 1.2$ \\
\hline $\mathrm{HO}\left(\mathrm{CH}_{2}\right)_{2} \mathrm{SH}, 10$ & 99.6 & 0.4 & $70.0 \pm 1.4$ & $0.6 \pm 0.1$ & $29.4 \pm 1.4$ \\
\hline $\mathrm{HO}\left(\mathrm{CH}_{2}\right)_{2} \mathrm{SH}, 100$ & 99.0 & 1.0 & $48.2 \pm 1.3$ & $3.5 \pm 0.4$ & $48.3 \pm 1.3$ \\
\hline $\mathrm{H}_{2} \mathrm{~S}, 10$ & 99.7 & 0.3 & $63.6 \pm 1.2$ & $0.2 \pm 0.1$ & $36.2 \pm 1.2$ \\
\hline $\mathrm{H}_{2} \mathrm{~S}, 100$ & 99.1 & 0.9 & $44.5 \pm 3.3$ & $0.6 \pm 0.1$ & $54.9 \pm 3.3$ \\
\hline
\end{tabular}

$1 \overline{\text { The values are means } \pm \text { standard deviation of } n=3 \text { experiments under the same conditions; }{ }^{2} \text { Errors }<0.1 ;}{ }^{3}$ Values are expressed as a relative percentage (\% rel) of each fatty acid isomer with respect to the starting cis fatty acid residue, estimated using calibration and 17:0 (heptadecanoic acid methyl ester) as an internal standard in the reaction mixture, after the transesterification of the fatty acid moieties composing POPC and CL and their quantification by GC.

We must underline the fact that, in our experiments, we kept the molarities of lipids and thiols (0.5-1 $\mathrm{mM}$ and $0.35 \mu \mathrm{M}$, respectively), as well as the nanomolar generation of radical species, closest to the biological ones. The results obtained with the POPC/CL mix similar to the mitochondrial ratio, with and without oxygen, indicate that both lipids can react under free radical conditions, with variable amounts of trans lipids formed depending on the conditions used. However, our models cannot straightforwardly reproduce the complexity of a real cellular environment.

\section{Conclusions}

The thiyl radical-catalyzed cis-trans isomerization of double bonds is a flexible methodology to achieve non-natural trans fatty acid derivatives of great importance for multidisciplinary aspects going from chemistry to molecular biology and medicine. Our results clarify the chemical reactivity under radiolysis and photolysis conditions of an important biomolecule, such as CL, involved in the function of mitochondria. We provide the first synthetic procedure for trans cardiolipin isomers that can be useful for experiments defining their biological effects. Our careful chemical analytical study provides important insights into protocols to identify trans CL isomers, highlighting tools such as GC and NMR and creating awareness on the mass data information for mitochondria evaluation, which cannot distinguish CL isomers having the same molecular mass [25,26]. Our protocols draw more attention for the work-up of biological samples required in lipidomics and metabolomics research.

Our results in the catalytic cycle of CL isomerization in solution and liposomes induced by thiyl radicals and the results obtained in biomimetic models under oxidative conditions can have a realistic application in biological systems, taking into account the molarity of lipids and different thiols in organisms. Our present data are limited to model experiments that must have confirmation for their application to biological systems. Two scenarios relevant for our data can be depicted: (i) the presence of $\mathrm{H}_{2} \mathrm{~S}$, at remarkable concentrations after its enzymatic production in mitochondria [55,56], and the isomerizing ability of its small diffusible radicals, such as $\mathrm{HS}^{\bullet}$ or the deprotonated form $\mathrm{S}^{\bullet-}$ [57], suggesting to monitor mitochondria with in vitro and in vivo experiments; (ii) the CL oxidation and the effects of several protective agents, monitored by the increase in CL contents [24], indicating the importance of a follow-up of CL isomerization under various stress conditions, in order to individuate antioxidants able to also preserve the natural cis double bond geometry [28]. The need for a multidisciplinary approach in the study of this interesting biomolecule clearly emerges.

Supplementary Materials: The following are available online at http://www.mdpi.com/2218-273X/10/8/1189/s1, Figure S1: ${ }^{1} \mathrm{H}$ NMR spectrum of natural bovine hearth cardiolipin in $\mathrm{CD}_{3} \mathrm{OD}$, Figure $\mathrm{S} 2:{ }^{13} \mathrm{C}$ NMR spectrum of natural bovine hearth cardiolipin in $\mathrm{CD}_{3} \mathrm{OD}$; Figure S3: GC analysis of the fatty acid methyl ester (FAME) residues obtained after isomerization of natural bovine hearth cardiolipin in $i$-PrOH for 4 min; Figure S4: The four possible 
mono-trans CL structures that are first formed in the step-by-step isomerization process, according to the external or internal fatty acid chain disposition. Figure S5: ${ }^{1} \mathrm{H}$ NMR spectrum in $\mathrm{CD}_{3} \mathrm{OD}$ of the reaction mix of CL isomerization after 4 min photolysis under the condition described in the Methods; Figure S6: Enlargement of two regions of the ${ }^{1} \mathrm{H}$ NMR spectrum shown in Figure S3. Up: the bis-allylic signals in CL (triplet at $2.78 \mathrm{ppm}$ ) and mono-trans CL (triplet at $2.72 \mathrm{ppm}$ ) together with their integration ratio (6.6: 1); Figure S7: ${ }^{13} \mathrm{C}$ NMR spectrum in $\mathrm{CD}_{3} \mathrm{OD}$ of the reaction mix of $\mathrm{CL}$ isomerization after 4 min photolysis under the condition described in the Methods. Figure S8: Enlargement of the ${ }^{13} \mathrm{C}$ NMR spectrum in $\mathrm{CD}_{3} \mathrm{OD}$ of the reaction mix of CL isomerization; Figure S9: Enlargement of the ${ }^{13} \mathrm{C}$ NMR spectrum in $\mathrm{CD}_{3} \mathrm{OD}$ evidencing the region of the alkyl carbon atoms; Figure $\mathrm{S} 10^{1} \mathrm{H}$ NMR spectrum in $\mathrm{CD}_{3} \mathrm{OD}$ of the reaction mix of CL isomerization after 20 min photolysis; Figure S11: ${ }^{13} \mathrm{C}$ NMR spectrum in $\mathrm{CD}_{4} \mathrm{OD}$ of the reaction mix of $\mathrm{CL}$ isomerization after 4 min photolysis; Figure S12: ${ }^{1} \mathrm{H}$ NMR spectra in $\mathrm{CD}_{3} \mathrm{OD}$ of CL (up) and Ag-CL complex (down); Figure $\mathrm{S}_{13}{ }^{1} \mathrm{H}$ NMR spectra in $\mathrm{CD}_{3} \mathrm{OD}$ of monotrans-CL (up) and mono-trans Ag-CL complex (down); Figure S14: Relative abundance (\%) of fatty acid moieties as function of the irradiation dose from the $\gamma$-radiolysis of bovine hearth CL; Figure S15: $\gamma$-Radiolysis of bovine hearth CL $(0.35 \mathrm{mM})$ in isopropanol; Figure S16. Relative abundance $(\%)$ of fatty acid moieties as function of the irradiation dose from the $\gamma$-radiolysis of $0.5 \mathrm{mM}$ POPC/CL liposomes; Figure S17. $\gamma$-radiolysis of $0.5 \mathrm{mM}$ POPC/CL liposomes (3: 1) in the presence of $0.5 \mathrm{mM} \mathrm{HO}\left(\mathrm{CH}_{2}\right)_{2} \mathrm{SH}$. Table S1: Transesterification experiments on cardiolipin; Table S2: Transesterification experiments on cardiolipin with NaOMe, Table S3. Transesterification experiments on POPC.

Author Contributions: Conceptualization, C.C. and C.F.; Formal analysis, F.V., A.S., C.M. and G.B.; Funding acquisition, C.F.; Methodology, F.V., A.S., M.R., C.C. and C.F.; Resources, C.C. and C.F.; Supervision, A.S., M.R. and C.F.; Writing-original draft, F.V., C.C. and C.F.; Writing-review \& editing, C.F., A.S., M.R. and C.C. All authors have read and agreed to the published version of the manuscript.

Funding: Funding of research provided by the Fondazione Di Bella is gratefully acknowledged.

Acknowledgments: The Fondazione Di Bella is gratefully acknowledged for the grant given to F.V.

Conflicts of Interest: The authors declare no conflict of interest.

\section{References}

1. Oteng, A.-B.; Kersten, S. Mechanism of action of trans fatty acids. Adv. Nutr. 2019, 11, 697-708. [CrossRef] [PubMed]

2. Chatgilialoglu, C.; Ferreri, C.; Melchiorre, M.; Sansone, A.; Torreggiani, A. Lipid geometrical isomerism: From chemistry to biology and diagnostics. Chem. Rev. 2014, 114, 255-284. [CrossRef] [PubMed]

3. Schneider, C.; Davies, S.S. Non enzymatic mechanisms of lipid oxidation. In Lipid Oxidation in Health and Disease; Spickett, C.M., Forman, H.J., Eds.; CRC Press: Boca Raton, FL, USA, 2015; Chapter 2. [CrossRef]

4. Kuhnt, K.; Baehr, M.; Rohrer, C.; Jahreis, G. Trans fatty acid isomers and the trans-9/trans-11 index in fat containing foods. Eur. J. Lipid Sci. Technol. 2011, 113, 1281-1292. [CrossRef] [PubMed]

5. Bannenberg, G.; Mallon, C.; Edwards, H.; Yeadon, D.; Yan, K.; Johnson, H.; Ismail, A. Omega-3 long-chain polyunsaturated fatty acid content and oxidation state of fish oil supplements in New Zealand. Sci. Rep. 2017, 7, 1488. [CrossRef]

6. Menounou, G.; Giacometti, G.; Scanferlato, R.; Dambruoso, P.; Sansone, A.; Tueros, I.; Amézaga, J.; Chatgilialoglu, C.; Ferreri, C. Trans lipid library: Synthesis of docosahexaenoic acid (DHA) monotrans isomers and regioisomer identification in DHA-containing supplements. Chem. Res. Toxicol. 2018, 31, 191-200. [CrossRef]

7. Houtkooper, R.H.; Vaz, F.M. Cardiolipin, the heart of mitochondrial metabolism. Cell Mol. Life Sci. 2008, 65, 2493-2506. [CrossRef]

8. Mileykovskaya, E.; Dowhan, W. Cardiolipin membrane domains in prokaryotes and eukaryotes. Biochim. Biophys. Acta Biomembr. 2009, 1788, 2084-2091. [CrossRef]

9. Paradies, G.; Paradies, V.; Ruggiero, F.M.; Petrosillo, G. Role of cardiolipin in mitochondrial function and dynamics in health and disease: Molecular and pharmacological aspects. Cells 2019, 8, 728. [CrossRef]

10. Huang, K.C.; Ramamurthi, K.S. Macromolecules that prefer their membranes curvy. Mol. Microbiol. 2010, 76, 822-832. [CrossRef]

11. Ye, C.; Shen, Z.; Greenberg, M.L. Cardiolipin remodeling: A regulatory hub for modulating cardiolipin metabolism and function. J. Bioenerg. Biomembr. 2016, 48, 113-123. [CrossRef]

12. Sam, P.N.; Avery, E.; Claypool, S.M. Proteolytic control of lipid metabolism. ACS Chem. Biol. 2019, 14, 2406-2423. [CrossRef] [PubMed] 
13. Bradley, R.M.; Stark, K.D.; Duncan, R.E. Influence of tissue, diet, and enzymatic remodeling on cardiolipin fatty acyl profile. Mol. Nutr. Food. Res. 2016, 60, 1804-1818. [CrossRef] [PubMed]

14. Kiebish, M.A.; Han, X.; Cheng, H.; Chuang, J.H.; Seyfried, T.N. Cardiolipin and electron transport chain abnormalities in mouse brain tumor mitochondria: Lipidomic evidence supporting the Warburg theory of cancer. J. Lipid Res. 2008, 49, 2545-2556. [CrossRef] [PubMed]

15. Lokhmatikov, A.V.; Voskoboynikova, N.; Cherepanov, D.A.; Skulachev, M.V.; Steinhoff, H.-J.; Skulachev, V.P.; Mulkidjanian, A.Y. Impact of antioxidants on cardiolipin oxidation in liposomes: Why mitochondrial cardiolipin serves as an apoptotic signal? Oxid. Med. Cell. Long. 2016, 2016, 8679469. [CrossRef] [PubMed]

16. Chatgilialoglu, C.; Ferreri, C. Trans lipids: The free radical path. Acc. Chem. Res. 2005, 38, 441-448. [CrossRef] [PubMed]

17. Chatgilialoglu, C.; Bowry, V.W. Why not trans? Inhibited radical isomerization cycles and coupling chains of lipids and alkenes with alkane-thiols. J. Org. Chem. Soc. 2018, 83, 9178-9189. [CrossRef] [PubMed]

18. Ferreri, C.; Costantino, C.; Perrotta, L.; Landi, L.; Mulazzani, Q.G.; Chatgilialoglu, C. Cis-trans isomerization of polyunsaturated fatty acid residues in phospholipids catalyzed by thiyl radicals. J. Am. Chem. Soc. 2001, 123, 4459-4468. [CrossRef]

19. Chatgilialoglu, C.; Ferreri, C.; Guerra, M.; Samadi, A.; Bowry, V.W. The reaction of thiyl radical with methyl linoleate: Completing the picture. J. Am. Chem. Soc. 2017, 139, 4704-4714. [CrossRef]

20. Tartaro Bujak, I.; Mihaljević, B.; Ferreri, C.; Chatgilialoglu, C. The influence of antioxidants in the thiyl radical induced lipid peroxidation and geometrical isomerization in micelles of linoleic acid. Free Radic. Res. 2016, 50, S18-S23. [CrossRef]

21. Christie, W.W.; Han, X. Lipid Analysis, 4nd ed.; The Oily Press: Bridgewater, UK, 2010; Part 1; pp. 21-54. ISBN 9780955251245.

22. Guan, Z.Z.; Söderberg, M.; Sindelar, P.; Edlund, C. Content and fatty acid composition of cardiolipin in the brain of patients with alzheimer's disease. Neurochem. Int. 1994, 25, 295-300. [CrossRef]

23. Lee, H.-J.; Mayette, J.; Rapoport, S.I.; Bazinet, R.P. Selective remodeling of cardiolipin fatty acids in the aged rat heart. Lipids Health Dis. 2006, 5, 2. [CrossRef] [PubMed]

24. Fouret, G.; Tolika, E.; Lecomte, J.; Bonafos, B.; Aoun, M.; Murphy, M.P.; Ferreri, C.; Chatgilialoglu, C.; Dubreucq, E.; Coudray, C.; et al. The mitochondrial-targeted antioxidant, MitoQ, increases liver mitochondrial cardiolipin content in obesogenic diet-fed rats. Biochim. Biophys. Acta Bioenerg. 2015, 147, 1025-1035. [CrossRef] [PubMed]

25. Hsu, F.-F.; Turk, J.; Rhoades, E.R.; Russell, D.G.; Shi, Y.; Groisman, E.A. Structural characterization of cardiolipin by tandem quadrupole and multiple-stage quadrupole ion-trap mass spectrometry with electrospray ionization. J. Am. Soc. Mass Spectr. 2005, 16, 491-504. [CrossRef] [PubMed]

26. Sparagna, G.C.; Johnson, C.A.; McCune, S.A.; Moore, R.L.; Murphy, R.C. Quantitation of cardiolipin molecular species in spontaneously hypertensive heart failure rats using electrospray ionization mass spectrometry. J. Lipid Res. 2005, 46, 1196-1204. [CrossRef] [PubMed]

27. Malhotra, A.; Xu, Y.; Ren, M.; Schlame, M. Formation of molecular species of mitochondrial cardiolipin. 1. A novel transacylation mechanism to shuttle fatty acids between sn-1 and sn-2 positions of multiple phospholipid species. Biochim. Biophys. Acta 2009, 1791, 314-320. [CrossRef] [PubMed]

28. Ting, H.-C.; Chen, L.-T.; Chen, J.-Y.; Huang, Y.-L.; Xin, R.-C.; Chan, J.-F.; Hsu, Y.-H.H. Double bonds of unsaturated fatty acids differentially regulate mitochondrial cardiolipin remodeling. Lipids Health Dis. 2019, 18, 53. [CrossRef]

29. Macias, L.A.; Feider, C.L.; Eberlin, L.S.; Brodbelt, J.S. Hybrid 193 nm ultraviolet photodissociation mass spectrometry localizes cardiolipin unsaturations. Anal. Chem. 2019, 91, 12509-12516. [CrossRef]

30. Fox, B.G.; Lyle, K.S.; Rogge, C.E. Reactions of the diiron enzyme stearoyl-acyl carrier protein desaturase. Acc. Chem. Res. 2004, 37, 421-429. [CrossRef]

31. Forman, B.M.; Chen, J.; Evans, R.M. Hypolipidemic drugs, polyunsaturated fatty acids, and eicosanoids are ligands for peroxisome proliferator-activated receptors alpha and delta. Proc. Natl. Acad. Sci. USA 1997, 94, 4312-4317. [CrossRef]

32. Jump, D.B.; Clarke, S.D. Regulation of gene expression by dietary fat. Annu. Rev. Nutr. 1999, 19, 63-90. [CrossRef] 
33. Ferreri, C.; Pierotti, S.; Barbieri, A.; Zambonin, L.; Landi, L.; Rasi, S.; Luisi, P.L.; Barigelletti, F.; Chatgilialoglu, C. Comparison of phosphatidylcholine vesicle properties related to geometrical isomerism. Photochem. Photobiol. 2006, 82, 274-280. [CrossRef] [PubMed]

34. Ferreri, C.; Pierotti, S.; Chatgilialoglu, C.; Barbieri, A.; Barigelletti, F. Probing the influence of cis-trans isomers on model lipid membrane fluidity using cis-parinaric acid and a stop-flow technique. Chem. Commun. 2006, 529-531. [CrossRef] [PubMed]

35. Tyler, A.I.I.; Greenfield, J.L.; Seddon, J.M.; Brooks, N.J.; Purushothaman, S. Coupling phase behavior of fatty acid containing membranes to membrane bio-mechanics. Front. Cell Dev. Biol. 2019, 7, 187. [CrossRef] [PubMed]

36. Chatgilialoglu, C.; Ferreri, C.; Torreggiani, A.; Renzone, G.; Salzano, A.M.; Scaloni, A. Radiation-induced reductive modifications of sulfur-containing amino acids within peptides and proteins. J. Proteomics 2011, 74, 2264-2273. [CrossRef]

37. Ferreri, C.; Kratzsch, S.; Brede, O.; Marciniak, B.; Chatgilialoglu, C. Trans lipid formation induced by thiols in human monocytic leukemia cells. Free Radic. Biol. Med. 2005, 38, 1180-1187. [CrossRef]

38. Cort, A.; Ozben, T.; Melchiorre, M.; Chatgilialoglu, C.; Ferreri, C.; Sansone, A. Effects of bleomycin and antioxidants on the fatty acid profile of testicular cancer cell membranes. Biochim. Biophys. Acta Biomembr. 2016, 1858, 434-441. [CrossRef]

39. Zambonin, L.; Ferreri, C.; Cabrini, L.; Prata, C.; Chatgilialoglu, C.; Landi, L. Occurrence of trans fatty acids in rats fed a trans-free diet: A free radical-mediated formation? Free Radic. Biol. Med. 2006, 40, 1549-1556. [CrossRef]

40. Marini, M.; Abruzzo, P.M.; Bolotta, A.; Veicsteinas, A.; Ferreri, C. Aerobic training affects fatty acid composition of erythrocyte membranes. Lipids Health Dis. 2011, 10, 188. [CrossRef]

41. Ferreri, C.; Chatgilialoglu, C. Membrane Lipidomics for Personalized Health; Wiley: Chichester, UK, 2015.

42. Sansone, A.; Melchiorre, M.; Chatgilialoglu, C.; Ferreri, C. Hexadecenoic fatty acid isomers: A chemical biology approach for human plasma biomarker development. Chem. Res. Toxicol. 2013, 26, 1703-1709. [CrossRef]

43. Sansone, A.; Tolika, E.; Louka, M.; Sunda, V.; Deplano, S.; Melchiorre, M.; Anagnostopoulos, D.; Chatgilialoglu, C.; Formisano, C.; Di Micco, R.; et al. Hexadecenoic fatty acid isomers in human blood lipids and their relevance for the interpretation of lipidomic profiles. PLoS ONE 2016, 11, e0152378. [CrossRef]

44. Ferreri, C.; Grabovskiy, S.A.; Aoun, M.; Melchiorre, M.; Kabal'nova, N.; Feillet-Coudray, C.; Fouret, G.; Coudray, C.; Chatgilialoglu, C. Trans fatty acids: Chemical synthesis of eicosapentaenoic acid isomers and detection in rats fed a deodorized fish oil diet. Chem. Res. Toxicol. 2012, 25, 687-694. [CrossRef] [PubMed]

45. Batzri, S.; Korn, E.D. Single bilayer liposomes prepared without sonication. Biochim. Biophys. Acta Biomembr. 1973, 298, 1015-1019. [CrossRef]

46. Spinks, J.W.T.; Woods, R.J. An Introduction to Radiation Chemistry, 3rd ed.; John-Wiley and Sons, Inc.: New York, NY, USA, 1990; p. 100.

47. Folch, J.; Lees, M.; Sloane Stanley, G.H. A simple method for the isolation and purification of total lipids from animal tissues. J. Biol. Chem. 1957, 226, 497-509. [PubMed]

48. Ferreri, C.; Samadi, A.; Sassatelli, F.; Landi, L.; Chatgilialoglu, C. Regioselective cis-trans isomerization of arachidonic double bonds by thiyl radicals: the influence of phospholipid supramolecular organization. J. Am. Chem. Soc. 2004, 126, 1063-1072. [CrossRef] [PubMed]

49. Bus, J.; Sies, I.; Lie Ken Jie, M.S.F. 13C-NMR of methyl, methylene and carbonyl carbon atoms of methyl alkenoates and alkynoates. Chem. Phys. Lipids 1976, 17, 501-518. [CrossRef]

50. Buxton, G.V.; Greenstock, C.L.; Helman, W.P.; Ross, A.B. Critical review of rate constants for reactions of hydrated electrons, hydrogen atoms and hydroxyl radicals $((\cdot \mathrm{OH}) / \mathrm{O}-)$ in aqueous solution. J. Phys. Chem. Ref. Data 1988, 17, 513-886. [CrossRef]

51. Ross, A.B.; Mallard, W.G.; Helman, W.P.; Buxton, G.V.; Huie, R.E.; Neta, P. NDRL-NIST Solution Kinetics Database: Ver. 3; Notre Dame Radiation Laboratory: Notre Dame, IN, USA; NIST Standard Reference Data: Gaithersburg, MD, USA, 1998.

52. Miller, D.M.; Buettner, G.R.; Aust, S.D. Transition metals as catalysts of "autoxidation" reactions. Free Radic. Biol. Med. 1990, 8, 95-108. [CrossRef]

53. Stohs, S.J.; Bagchi, D. Oxidative mechanisms in the toxicity of metal ions. Free Radic. Biol. Med. 1995, 18, 321-336. [CrossRef] 
54. Mihaljević, B.; Tartaro, I.; Ferreri, C.; Chatgilialoglu, C. Linoleic acid peroxidation vs. isomerization: A biomimetic model of free radical reactivity in the presence of thiols. Org. Biomol. Chem. 2011, 9, 3541-3548.

55. Fu, M.; Zhang, W.; Wu, L.; Yang, G.; Li, H.; Wang, R. Hydrogen sulfide (H2S) metabolism in mitochondria and its regulatory role in energy production. Proc. Natl. Acad Sci. 2012, 109, 2943-2948. [CrossRef]

56. Filipovic, M.R.; Zivanovic, J.; Alvarez, B.; Benerjee, R. Chemical biology of H2S signaling through persulfidation. Chem. Rev. 2018, 118, 1253-1337. [CrossRef] [PubMed]

57. Lykakis, I.N.; Ferreri, C.; Chatgilialoglu, C. The sulfhydryl radical (HS• and S•-): A contender for the isomerization of double bonds in membrane lipids. Angew. Chem. Int. Ed. 2007, 46, 1914-1916. [CrossRef] [PubMed]

(C) 2020 by the authors. Licensee MDPI, Basel, Switzerland. This article is an open access article distributed under the terms and conditions of the Creative Commons Attribution (CC BY) license (http://creativecommons.org/licenses/by/4.0/). 